\title{
PENINGKATAN PENGETAHUAN TENTANG DAGUSIBU TERHADAP KADER GERAKAN KELUARGA SADAR OBAT (GKSO) DESA TANJUNG GUNUNG BANGKA TENGAH
}

\author{
Rachmawati Felani Djuria \\ Poltekkes Kemenkes Pangkalpinang \\ felanDJ87@gmail.com: jkp.pangkalpinang@gmail.com
}

\begin{abstract}
Abstrak
Hasil studi pendahuluan yang telah dilakukan oleh tim dosen dan mahasiswa ke Desa Binaan Desa Tanjung Gunung yang menunjukkan bahwa pengetahuan masyarakat di Desa Tanjung Gunung tentang penggunaan obat khususnya pengelolaan obat dalam keluarga kurang. Selain itu, hasil penelitian Oktaviani (2017), menunjukkan bahwa pengetahuan masyarakat di Desa Tanjung Gunung tentang penggunaan obat antimalaria kurang. Tujuan penelitian ini adalah meningkatkan pengetahuan tentang DAGUSIBU di Desa Tanjung Gunung Kabupaten Bangka Tengah Provinsi Kepulauan Bangka Belitung dengan metode Cara Belajar Ibu Aktif (CBIA). Metode yang digunakan adalah eksperimental murni pendekatan kuantitatif menggunakan prestest-posttest only control group design. Penelitian dilaksanakan pada bulan Maret-Juni tahun 2018. Jumlah sampel yang digunakan adalah total sampling (populasi). Hasil penelitian menunjukkan bahwa metode CBIA dapat meningkatkan pengetahuan kader GKSO tentang DAGUSIBU di Desa Tanjung Gunung Kabupaten Bangka Tengah Provinsi Kepulauan Bangka Belitung sebanyak 61,54\%. Ada perbedaan yang signifikan antara pengetahuan sebelum dilakukan CBIA dan sesudah dilakukan CBIA dengan p-value 0,021. Sarannya mengaktifkan kader GKSO yang telah dibentuk serta mendayagunkan tim fasilitator dalam peningkatan pengetahuan tentang obat.
\end{abstract}

Kata kunci : Pengetahuan, DAGUSIBU, Gerakan Keluarga Sadar Obat

\section{INCREASED KNOWLEDGE ABOUT DAGUSIBU TO CADRES CONSCIOUS FAMILY MEDICINE (GKSO) IN TANJUNG GUNUNG VILLAGE CENTRAL BANGKA REGENCY}

\begin{abstract}
The results of the preliminary study conducted by the lecturer and student team to the Village Patronage of Tanjung Gunung Village showed that the knowledge of the people in Tanjung Gunung Village about the use of drugs especially the management of drugs in the family was lacking. In addition, the results of Oktaviani's (2017) study show that the knowledge of the people in Tanjung Gunung Village about the use of antimalarial drugs is lacking. The purpose of this study was to increase knowledge about DAGUSIBU in Tanjung Gunung Village, Central Bangka Regency, Bangka Belitung Islands Province, using the method of Active Mothers Learning (CBIA). The method used is a pure experimental quantitative approach using the prestest-posttest only control group design. The study was conducted in March-June 2018. The number of samples used was total sampling (population). The results showed that the CBIA method could increase the knowledge of GKSO cadres about DAGUSIBU in Tanjung Gunung Village, Central Bangka Regency, Bangka Belitung Islands Province as much as $61.54 \%$. There was a significant difference between knowledge before CBIA was conducted and after CBIA was conducted with p-value 0.021. His advice was to activate the GKSO cadres that had been formed and to use the facilitator team in increasing knowledge about drugs.
\end{abstract}

Keywords: Knowledge, DAGUSIBU, Cadres Consscious Family Medicine 
PENDAHULUAN

Berdasarkan hasil studi pendahuluan yang telah dilakukan oleh tim dosen dan mahasiswa ke Desa Binaan Desa Tanjung Gunung menunjukkan bahwa pengetahuan masyarakat di Desa Tanjung Gunung tentang penggunaan obat khususnya pengelolaan obat dalam keluarga kurang. Selain itu, hasil peneltian Oktaviani (2017), menunjukkan bahwa pengetahuan masyarakat di Desa Tanjung Gunung tentang penggunaan obat antimalaria kurang.

Penelitian Tiara (2015), juga masih menunjukkan ada ibu rumah tangga yang berpengatahuan kurang tentang penyimpanan obat swamedikasi yakni sebanyak 36 orang (9\%). Pengetahuan yang kurang adalah tentang suhu dan sediaan penyimpanan obat swamedikasi. Sari, dkk (2015), juga menyebutkan bahwa masyarakat seringkali tidak peduli dengan tata cara pengelolaan obat karena yang diketahui hanyalah istilah obat untuk dikonsumsi agar sembuh.

Masyarakat Indonesia saat ini sudah mulai terbiasa dengan penggunaan berbagai jenis obat-obatan dengan tujuan menyembuhkan penyakit, mengontrol ataupu suplemen untuk menunjang aktifitas seharihari. Dampak negatif dari hal ini adalah kesalahan dalam menggunakan hingga membuang limbah obat. Hal ini dapat terjadi karena kurangnya pengetahuan dan informasi yang disampaikan kepada masyarakat terkait penggunaan obat yang baik dan benar. Kesalahan dalam penggunaan obat dapat menyebabkan kerugian baik bagi masyarakat maupun bagi lingkungan (Maziyyah, 2015).

Oleh karena itu, Ikatan Apoteker Indonesia (IAI) sebagai salah satu organisasi profesi kesehatan saai ini mulai mencanangkan kegiatan penyuluhan kepada masyarakat terkait penggunaan obat yang baik dan benar. Kegiatan tersebut diberi nama DAGUSIBU (Dapatkan - Gunakan- Simpan - Buang). Apoteker sebagai profesi kesehatan yang fokus dalam pemakaian obat-obatan di masyarakat dihimbau untuk terus melakukan penyuluhan DAGUSIBU (Maziyyah, 2015). Menurut Djuria (2015), DAGUSIBU adalah suatu motto untuk mendapatkan, menggunakan, menyimpan dan membuang obat dengan benar.

Selain itu, Kementrian Kesehatan juga sekarang menggiatkan program Gema Cermat (Gerakan Masyarakat Cerdas Menggunakan Obat) dengan membentuk Gerakan Keluarga
Sadar Obat (GKSO). Menurut Mafruhah, Diesty dan Sita (2016), edukasi Cara Belajar Ibu Aktif (CBIA) dapat meningkatkan pengetahuan tentang obat common cold yang dilakukan secara swamedikasi sebesar $81,6 \%$. Helni (2018), juga menunjukkan bahwa metode CBIA dapat meningkatkan pengetahuan dan ketrampilan pada swamedikasi. Berdasarkan hasil studi pendahuluan serta hasil penelitian tersebut, maka perlu dilakukan peningkatan pengetahuan tentang DAGUSIBU terhadap kader GKSO dengan metode CBIA di Desa Tanjung Gunung Kabupaten Bangka Tengah Provinsi Kepulauan Bangka Belitung.

\section{METODE}

Metode yang digunakan adalah eksperimental murni pendekatan kuantitatif menggunakan prestest-posttest only control group design dengan metode intervensi adalah CBIA. Penelitian dilaksanakan pada bulan Maret-Juni tahun 2018. Jumlah sampel yang digunakan adalah total sampling (populasi) yakni sebanyak 23 orang kader GKSO.

\section{HASIL}

Hasil penelitian menunjukkan bahwa sebagai berikut:

1. Demografi Responden

Tabel 1. Karakteristik Demografi Kader Gerakan Keluarga Sadar Obat (GKSO) Di Desa Tanjung Gunung Bangka Tengah

\begin{tabular}{|c|c|c|}
\hline Kategori & Jumlah & $\%$ \\
\hline \multicolumn{3}{|l|}{ 1. Umur } \\
\hline a. Dewasa (18-40 tahun) & 15 & 65,22 \\
\hline b. Tua (41-75 tahun) & 8 & 34,78 \\
\hline Total & 23 & 100 \\
\hline \multicolumn{3}{|l|}{ 2. Pendapatan } \\
\hline a. $\operatorname{Rendah}(<1,5 \mathrm{jt})$ & 21 & 91,30 \\
\hline b. Sedang $(1,5 \mathrm{jt}-2,5 \mathrm{jt})$ & 2 & 8,70 \\
\hline c. Tinggi $(2,5 \mathrm{jt}-3,5 \mathrm{jt})$ & 0 & 0 \\
\hline d. Sangat tinggi $(>3,5 \mathrm{jt})$ & 0 & 0 \\
\hline Total & 23 & 100 \\
\hline \multicolumn{3}{|l|}{ 3. Pekerjaan } \\
\hline a. Ibu Rumah Tangga & 18 & 78,26 \\
\hline b. Non PNS & 5 & 21,74 \\
\hline Total & 23 & 100 \\
\hline \multicolumn{3}{|l|}{ 4. Sumber Informasi } \\
\hline a. 1 media & 19 & 82,61 \\
\hline b. 2 media & 3 & 13,04 \\
\hline c. 3 media & 1 & 4,35 \\
\hline Total & 23 & 100 \\
\hline \multicolumn{3}{|l|}{ 5. Pendidikan } \\
\hline $\begin{array}{ll}\text { a. } & \text { Rendah (Tidak } \\
& \text { Sekolah-SMP) }\end{array}$ & 20 & 86,96 \\
\hline b. Tinggi (SMA-PT) & 3 & 13,04 \\
\hline Total & 23 & 100 \\
\hline
\end{tabular}

Sumber : Data Primer yang telah diolah (2018) 
Berdasarkan Tabel 1 di atas, paling banyak kader $(65,22 \%)$, berpendapatan rendah sebanyak 21 orang $(91,30 \%)$ dan berpekerjaan sebagai Ibu Rumah Tangga sebanyak 18 orang $(78,26 \%)$ serta berpendidikan rendah sebanyak 20 orang $(86,96 \%)$. Selain itu, kader mendapatkan informasi tentang DAGUSIBU paling banyak dari 1 media yakni 19 orang $(82,61 \%)$ yang secara rinci media cetak sebanyak 2 orang $(10,53 \%)$, elektronik sebanyak 5 orang $(26,32 \%)$ dan non media sebanyak 12 orang $(63,15 \%)$.

Tabel 2. Hasil Pengukuran Pengetahuan

Tentang "DAGUSIBU" Terhadap Kader GKSO Desa Tanjung Gunung Bangka Tengah

\begin{tabular}{|c|c|c|c|c|}
\hline NO & Nama & $\begin{array}{c}\text { Jawaban } \\
\text { Benar Pre } \\
\text { Test }\end{array}$ & $\begin{array}{c}\text { Jawaban } \\
\text { Benar Post } \\
\text { Test }\end{array}$ & Selisih \\
\hline 1 & A & 70 & 60 & -10 \\
\hline 2 & B & 20 & 70 & 50 \\
\hline 3 & C & 30 & 70 & 40 \\
\hline 4 & D & 40 & 70 & 30 \\
\hline 5 & E & 60 & 70 & 10 \\
\hline 6 & F & 70 & 80 & 10 \\
\hline 7 & G & 70 & 70 & 0 \\
\hline 8 & H & 40 & 80 & 40 \\
\hline 9 & J & 30 & 100 & 70 \\
\hline 10 & K & 60 & 50 & -10 \\
\hline 11 & L & 10 & 100 & 90 \\
\hline 12 & N & 60 & 50 & -10 \\
\hline 13 & O & 60 & 60 & 0 \\
\hline 14 & I & 50 & 0 & -50 \\
\hline 15 & M & 90 & 0 & -90 \\
\hline 16 & V & 50 & 0 & -50 \\
\hline 17 & P & 0 & 80 & 80 \\
\hline 18 & Q & 0 & 30 & 30 \\
\hline 19 & R & 0 & 60 & 60 \\
\hline 20 & S & 0 & 60 & 60 \\
\hline 21 & T & 0 & 60 & 60 \\
\hline 22 & W & 0 & 70 & 70 \\
\hline 23 & X & 0 & 70 & 70 \\
\hline Rata-rata & 35,22 & 59,13 & 23,91 \\
\hline & Rata-rata gap keseluruhan & 23,91 \\
\hline
\end{tabular}

Berdasarkan Tabel 2 di atas, dapat dilihat bahwa terdapat 15 kader $(65,22 \%)$ mengalami peningkatan pengetahuan, 2 orang kader $(8,69 \%)$ konstan/tidak berubah dan 6 orang kader $(26,08 \%)$ yang mengalami penurunan pengetahuan.
Tabel 2 juga menunjukkan bahwa ratarata jawaban benar pada pre test 35,22 yang masuk dalam kategori pengetahuan kurang dan pada post test rata-rata jawaban benar 59,13 masuk dalam kategori pengetahuan cukup. Hasil ini menunjukkan bahwa metode CBIA dapat meningkatkan pengetahuan. Sebagian besar kader GKSO meningkat pengetahuannya dengan rata-rata gap/selisihnya adalah 23,91.

Tabel 3. Hasil Uji Statistik Evaluasi Kegiatan Pembentukan Kader Gerakan Keluarga Sadar Obat (GKSO) Dengan Metode Cara Belajar Ibu Aktif (CBIA) Tentang "DAGUSIBU" Di Desa Tanjung Gunung Bangka Tengah

\begin{tabular}{|c|c|c|c|c|c|c|c|c|}
\hline & \multicolumn{5}{|c|}{ Paired Differences } & \multirow[b]{3}{*}{$\mathrm{T}$} & \multirow[b]{3}{*}{$\mathrm{df}$} & \multirow{3}{*}{$\begin{array}{c}\text { Sig. } \\
(2- \\
\text { tailed } \\
\quad)\end{array}$} \\
\hline & \multirow[b]{2}{*}{$\begin{array}{c}\text { Mea } \\
\mathrm{n}\end{array}$} & \multirow{2}{*}{$\begin{array}{c}\text { Std. } \\
\text { Devia } \\
\text { tion }\end{array}$} & \multirow{2}{*}{$\begin{array}{l}\text { Std. } \\
\text { Error } \\
\text { Mean }\end{array}$} & \multicolumn{2}{|c|}{$\begin{array}{c}95 \% \\
\text { Confiden } \\
\text { ce } \\
\text { Interval } \\
\text { of the } \\
\text { Differenc } \\
\text { e }\end{array}$} & & & \\
\hline & & & & $\begin{array}{c}\text { Lo } \\
\text { wer }\end{array}$ & $\begin{array}{c}\mathrm{Upp} \\
\text { er }\end{array}$ & & & \\
\hline $\begin{array}{ll}\text { Pair } 1 & \text { Pengetah } \\
& \text { uan } \\
& \text { sebelum } \\
& \text { dilakukan } \\
\text { CBIA - } & \\
\text { pengetah } \\
\text { uan } \\
\text { sesudah } \\
\text { dilakukan } \\
\text { CBIA }\end{array}$ & $\begin{array}{r}- \\
23.8 \\
46\end{array}$ & $\begin{array}{r}32.54 \\
2\end{array}$ & 9.025 & $\begin{array}{r}- \\
43.5 \\
11\end{array}$ & $\begin{array}{r}- \\
4.18 \\
1\end{array}$ & $\begin{array}{r}- \\
2.64 \\
2\end{array}$ & 12 & .021 \\
\hline
\end{tabular}

Berdasarkan Tabel 3 di atas, dapat dilihat bahwa nilai $p$ value signifikansi sebesar 0,021 . Hal ini menunjukkan bahwa ada perbedaan yang signifikan antara pengetahuan Kader GKSO tentang DAGUSIBU sebelum dilakukan CBIA dengan sesudah dilakukan CBIA.

\section{PEMBAHASAN}

Hasil penelitian menunjukkan bahwa terdapat 15 kader $(65,22 \%)$ mengalami peningkatan pengetahuan, 2 orang kader $(8,69 \%)$ konstan/tidak berubah dan 6 orang kader $(26,08 \%)$ yang mengalami penurunan pengetahuan. Penurunan pengetahuan ini mungkin dikarenakan peserta kurang konsentrasi karena sudah ingin pulang ke rumah karena sudah siang dan tidak diisi mungkin terlangkah karena terburu-buru dalam pengisian sehingga kosong tidak terjawab.

Hasil juga menunjukkan bahwa rata-rata jawaban benar pada pre test 35,22 yang masuk dalam kategori pengetahuan kurang dan pada 
post test rata-rata jawaban benar 59,13 masuk dalam kategori pengetahuan cukup. Hasil ini menunjukkan bahwa metode CBIA dapat meningkatkan pengetahuan. Sebagian besar kader GKSO meningkat pengetahuannya dengan rata-rata gap/selisihnya adalah 23,91. Nilai $p$ value signifikansi sebesar 0,021 . Hal ini menunjukkan bahwa ada perbedaan yang signifikan antara pengetahuan Kader GKSO tentang DAGUSIBU sebelum dilakukan CBIA dengan sesudah dilakukan CBIA.

Peningkatan pengetahuan kader GKSO juga dipengaruhi oleh faktor umur. Hal ini dapat dilihat dari paling banyak peserta berumur dewasa yakni sebanyak 15 orang $(65,22 \%)$. Pada umur yang tua, faktor daya ingat sangat mempengaruhi pengetahuan seseorang (Notoatmodjo, 2010). Hurclock dalam Wawan dan Dwei (2010), juga menjelaskan semakin cukup usia, tingkat kematangan dan kekuatan seseorang akan lebih matang dalam berfikir dan bekerja.

Begitu juga, faktor pekerjaan dan pendapatan/pengahasilan juga mempengaruhi pengetahuan seseorang. Kader GKSO paling banyak tidak bekerja (sebagai ibu rumah tangga) yakni sebanyak 18 orang $(78,26 \%)$. Kategori pendapatan kader GKSO paling banyak berpendapatan rendah sebanyak 21 orang $(91,30 \%)$.

Menurut Notoatmodjo (2010), semakin besar pendapatan sesorang maka semakin meningkat pengetahuannya. Hal ini dikarenakan dengan penghasilan tersebut seseorang mempunyai kesempatan untuk memenuhi kebutuhan sarana dan prasarana terkait pengetahuan. Faktor lain yang mempengaruhi juga adalah pendidikan. Pendidikan kader GKSO paling banyak berpendidikan rendah sebanyak 20 orang $(86,96 \%)$. Secara kategori, pendidikan rendah ini adalah tidak sekolah, tamat SD dan tamat SMP. Oleh karena itu, Kader GKSO rata-rata berpengetahan kurang pada waktu pre test.

Selain itu, faktor sumber informasi juga mempengaruhi pengetahuan, semakin banyak sumber informasi yang diperoleh pengetahuan juga akan meningkat. Peserta mendapatkan informasi tentang DAGUSIBU paling banyak dari 1 media yakni 19 orang $(82,61 \%)$ yang secara rinci media cetak sebanyak 2 orang $(10,53 \%)$, elektronik sebanyak 5 orang $(26,32 \%)$ dan non media sebanyak 12 orang $(63,15 \%)$. Sumber informasi non media yang dimaksud adalah dari tenaga kesehatan, tetangga dan keluarga. Informasi yang sering dibaca oleh kader GKSO dalam brosur obat adalah aturan pakai dan indikasi. Obat yang pernah digunakan sebelum kegiatan adalah obat golongan antibiotik, obat analgetik dan antipiretik serta obat yang mengobati magh dan batuk.

Kegiatan CBIA berhasil meningkatkan pengetahuan kader GKSO tentang obat golongan analgetik dan antipiretik serta antibiotik. Hal ini dapat dilihat dari Tabel 5 yang menunjukkan terjadi peningkatan jumlah benar dalam membandingkan nilai pre test dan post test (pertanyaan 4 dan 7).

Hasil evaluasi peningkatan pengetahuan melalui metode CBIA ini sesuai dengan penelitian Susilowati (2012), yang menunjukkan bahwa pelatihan CBIA juga mampu meningkatkan pengetahuan informasi obat pada ibu anggota Ikatan Istri Karyawan Pindad (IIKP) Turen dengan peningkatan sebesar $68,66 \%$. Begitu juga hasil penelitian Helni (2018) yang menunjukkan bahwa metode CBIA dapat meningkatkan pengetahuan dan ketrampilan pada swamedikasi. Mafruhah, Diesty dan Sita (2016), juga menunjukkan metode CBA dapat meningkatkan tingkat pengetahuan kelompok perlakuan secara signifikan dengan $\mathrm{p}$ value 0,000 . Perbedaan tingkat pengetahuan yang signifikan juga terjadi antara kelompok kontrol dan kelompok perlakukan dengan $\mathrm{p}$ value 0,000 . Kategori baik pada kelompok perlakuan meningkat menjadi $81,6 \%$.

Witri, Agustin dan Muhammad (2017), menyebutkan bahwa metode CBIA berpengaruh signifikan terhadap pengetahuan tentang informasi obat selesma degan nilai probilitas 0,000 sehingga Ho ditolak yang berarti pelatihan CBIA berpengaruh secara signifikan meningkatkan pengetahuan. Arfian, Sri dan Rustamaji (2016), juga menyebutkan intervensi CBIA pada ibu-ibu kelompok BKB meningkatkan pengetahuan, sikap dan perilaku penggunaan antibiotik yang rasional. Penelitian Hartayu, Mohamed dan Sri (2010), pun menunjukkan metode CBIA-DM efektif untuk meningkatkan pengetahuan dan sikap terhadap pola hidup sehat pada penderita diabetes mellitus tipe 2. Lathifah, dkk (2015), menunjukkan bahwa terdapat perbedaan bermakna secara statistik pengetahuan antara sebelum dan sesudah perlakuan dengan menggunakan metode CBIA maupun FGD. 


\section{SIMPULAN}

1. Metode Cara Belajar Ibu Aktif (CBIA) tentang "DAGUSIBU" di Desa Tanjung Gunung Bangka Tengah dapat meningkatkan pengetahuan kader GKSO sebanyak $65,22 \%$.

2. Terdapat perbedaan yang signifikan antara pengetahuan kader GKSO sebelum dilakukan CBIA dan sesudah dilakukan CBIA dengan nilai $p$ value sebesar 0,021 .

\section{SARAN}

1. Mengaktifkan kader GKSO yang telah dibentuk dan mendayagunakan tim fasilitator dalam peningkatan pengetahuan tentang obat di masyarakat.

2. Bekerjasama dengan kampus dalam peningkatan pengetahuan masyarakat.

\section{UCAPAN TERIMA KASIH}

Ucapan terimakasih ditujukan kepada Poltekkes Kemenkes Pangkalpinang yang telah memberikan dana dalam pelaksanaan kegiatan ini.

\section{DAFTAR PUSTAKA}

Arfian, B,M, Sri S, dan Rustamaji. 2016. Intervensi CBIA untuk Meningkatkan Pengetahuan, Sikap dan Perilaku Penggunaan Antibiotik yang Rasional pada Anggota Bina Keluarga Balita. Jurnal Kedokteran Brawijaya Vol 29, Agustus 2016. Jawa Timur.

Djuria, R.F. 2015. Penyuluhan Tata Laksana Pelayanan Informasi Obat (PIO) "DAGUBISU". Laporan Kegiatan Pengabdian Masyarakat. Jurusan Farmasi. Poltekkes Kemenkes RI Pangkalpinang. Bangka Belitung.

Hartayu, Mohamed dan Sri. 2010. Efektivitas Metode Cara Belajar Insan Aktif untuk Diabetes Mellitus (CBIA-DM) dalam Meningkatkan Pengetahuan dan Sikap Terhadap Pola Hidup Sehat pada Penyandang Diabetes Mellitus Tipe 2 di Yogyakarta Indonesia. Jurnal Farmasi Sains dan Komunitas Volume VII No 2, November 2010. Univeristas Sanata Dharma. Yogyakarta.

Helni. 2018. Pengaruh Metode CBIA (Cara Belajar Ibu Aktif) Terhadap Peningkatan Pengetahuan dan Ketrampilan Pada Swamedikasi di Kota Jambi. Bagian Farmasi. Program Studi Ilmu Kedokteran FKIK Universitas Jambi. Jambi.
Hurlock, E.B. 1998. Psikologi Perkembangan: Suatu Pendekatan Sepanjang Tentang Kehidupan. Erlangga. Jakarta.

Lathifah, M.A., Susanti., Much.Ilham dan Aji Wibowo. 2015. Perbandingan Metode CBIA dan FGD dalam Peningkatan Pengetahuan dan Ketepatan Caregiver dalam Upaya Swamedikasi Demam pada Anak. Original Article Pharm Sci Res ISSN 2407-2354. August 2015 (Vol 2 No 2).

Mafruhah, O.R, Diesty, A.N, Sita, R.S. 2016. Pengaruh Edukasi CBIA (Cara Belajar Ibu Aktif) Terhadap Tingkat Pengetahuan Obat Common Cold di Desa. Jurnal Manajemen dan Pelayanan Farmasi. Prodi Famasi, Fakultas MIPA, Universitas Islam Indonesia. Yogyakarta.

Mazziyah, N. 2015. Penyuluhan Penggunaan Obat Yang Benar (DAGUSIBU) di Padukuhan Bakalan, Mlati, Sleman, Yogyakarta. Laporan Kegiatan Pengabdian Masyarakat. Program Studi Farmasi. Fakultas Kedokteran dan Ilmu Kesehatan. Universitas Muhammadiyah Yogyakarta. Yogyakarta.

Notoatmodjo, S. 2010. Metodologi Penelitian Kesehatan. PT.Rineka Cipta. Jakarta.

Oktaviani, H. 2017. Gambaran Pengetahuan Masyakarat Tentang Penggunaan Obat Anti Malaria di Desa Tanjung Gunung. Karya Tulis Ilmiah. Jurusan Farmasi. Poltekkes Kemenkes RI Pangkalpinang. Bangka Belitung.

Sari, dkk. 2015. Kurangnya Pengetahuan Masyarakat Mengenai DAGUSIBU. Makalah Bahasa Indonesia. Fakultas Farmasi. Universitas Airlangga. Surabaya.

Susilowati, E. 2012. Peningkatan Pengetahuan Informasi Obat Pada Anggota Ikatan Istri Karyawan Pindad (IIKP) Turen Melalui Metode Cara Belajar Ibu Aktif (CBIA). Artikel Penelitian. Akademi Farmasi Putra Indonesia Malang. Jawa Timur.

Tiara, B. 2015. Gambaran Pengetahuan Tentang Penyimpanan Obat Swamedikasi Pada Ibu Rumah Tangga di Kelurahan Parit Padang Kecamatan Sungailiat Kabupaten Bangka Tahun 2015. Karya Tulis Ilmiah. Jurusan Farmasi. Poltekkes Kemenkes RI Pangkalpinang. Bangka Belitung.

Witri, Agustin dan Muhammad. 2017. Pengaruh Metode CBIA (Cara Belajar 
Insan Aktif) terhadap Pengethuan Informasi Obat Selesmas Pada Anggota Karang Taruna Dusun Wanujoyo Lor Srimartani Piyungan Bantul. Jurnal Ilmu Kesehatan Bhakti Setya Medika Vol 2 September 2017. Yogyakarta. 